\title{
Cost-effectiveness analysis of neonatal hearing screening program in china: should universal screening be prioritized?
}

Li-Hui Huang ${ }^{1,2+}$, Luo Zhang ${ }^{1,2+}$, Ruo-Yan Gai Tobe ${ }^{3,5}$, Fang-Hua Qi ${ }^{4}$, Long Sun ${ }^{5}$, Yue Teng ${ }^{5}$, Qing-Lin Ke ${ }^{5}$, Fei Mai ${ }^{6}$, Xue-Feng Zhang ${ }^{7}$, Mei Zhang ${ }^{8}$, Ru-Lan Yang ${ }^{9}$, Lin Tu ${ }^{10}$, Hong-Hui Li ${ }^{11}$, Yan-Qing Gu ${ }^{12}$, Sai-Nan Xu ${ }^{13}$, Xiao-Yan Yue ${ }^{14}$, Xiao-Dong Li ${ }^{15}$, Bei-Er Qi ${ }^{1,2}$, Xiao-Huan Cheng ${ }^{1,2}$, Wei Tang ${ }^{4}$, Ling-Zhong Xu ${ }^{*}$ and De-Min Han ${ }^{1,2^{*}}$

\begin{abstract}
Background: Neonatal hearing screening (NHS) has been routinely offered as a vital component of early childhood care in developed countries, whereas such a screening program is still at the pilot or preliminary stage as regards its nationwide implementation in developing countries. To provide significant evidence for health policy making in China, this study aims to determine the cost-effectiveness of NHS program implementation in case of eight provinces of China.

Methods: A cost-effectiveness model was conducted and all neonates annually born from 2007 to 2009 in eight provinces of China were simulated in this model. The model parameters were estimated from the established databases in the general hospitals or maternal and child health hospitals of these eight provinces, supplemented from the published literature. The model estimated changes in program implementation costs, disability-adjusted life years (DALYs), average cost-effectiveness ratio (ACER), and incremental cost-effectiveness ratio (ICER) for universal screening compared to targeted screening in eight provinces.
\end{abstract}

Results and discussion: A multivariate sensitivity analysis was performed to determine uncertainty in health effect estimates and cost-effectiveness ratios using a probabilistic modeling technique. Targeted strategy trended to be cost-effective in Guangxi, Jiangxi, Henan, Guangdong, Zhejiang, Hebei, Shandong, and Beijing from the level of 9\%, $9 \%, 8 \%, 4 \%, 3 \%, 7 \%, 5 \%$, and $2 \%$, respectively; while universal strategy trended to be cost-effective in those provinces from the level of $70 \%, 70 \%, 48 \%, 10 \%, 8 \%, 28 \%, 15 \%, 4 \%$, respectively. This study showed although there was a huge disparity in the implementation of the NHS program in the surveyed provinces, both universal strategy and targeted strategy showed cost-effectiveness in those relatively developed provinces, while neither of the screening strategy showed cost-effectiveness in those relatively developing provinces. This study also showed that both strategies especially universal strategy achieve a good economic effect in the long term costs.

Conclusions: Universal screening might be considered as the prioritized implementation goal especially in those relatively developed provinces of China as it provides the best health and economic effects, while targeted screening might be temporarily more realistic than universal screening in those relatively developing provinces of China.

\footnotetext{
*Correspondence: xulzsddx@163.com; trhos.handm@gmail.com

+ Contributed equally

${ }^{1}$ Beijing Tongren Hospital, Capital Medical University, Beijing, China

${ }^{5}$ Institute of Social Medicine and Health Services Management, School of

Public Health, Shandong University, Wen-hua-xi Road No.44, Jinan City,

Shandong Province 250012, China

Full list of author information is available at the end of the article
} 


\section{Background}

As adequate auditory stimulation in early childhood is fundamental for optimal speech and language development as well as for the acquisition of literacy skills, early hearing detection and interventions for deaf children are essential $[1,2]$. A failure to undertake early hearing detection and intervention within the first year of life for permanent congenital and early-onset hearing impairment (PCEHI) might lead to severe and irreversible impairment in language acquisition and speech development in early life and poor educational and occupational performance in adulthood [3-7]. However, compared to those major disease set out in the Millennium Development Goals, PCEHI, as a non-fatal but life-long disease, has been neglected particularly in developing countries [8-10].

Neonatal hearing screening (NHS) program has made a rapid development in recent years. The benefit of NHS is that it allows most PCEHI to be detected early enough for optimal intervention $[11,12]$. NHS has been routinely offered as a vital component of early childhood care in developed countries, whereas such a screening program is still at the pilot or preliminary stage as regards its nationwide implementation in developing countries where hearing care services, such as the provision of hearing aids, only cover approximately $1 \%$ of all the population [13].

Cost-effectiveness analysis (CEA) has been used as a tool to prioritize scarce health resources, which allows the comparison of various intervention options $[14,15]$. Although CEA is currently the cornerstone of health investment, it might be the only one approach implemented in the developing countries in Africa and Asia to evaluate selected interventions for hearing impairment [16]. The prospects of any immediate action to implement NHS programs are still uncertain in most of developing countries, since the current approach to global disease prioritization and health resource allocation requires vital data in an environment where funds to invest are always scarce.

In China, the largest developing country in the world, the Ministry of Health has recently decided to address the issue of non-fatal congenital diseases in neonatal health care which have until now been neglected but have a considerable impact on the individual, family and society. There is now a political commitment to scale-up a hospital-based neonatal hearing screening program, which will include expanded screening, diagnosis and intervention services [17]. A key policy question on how to implement the program under a system of decentralized health financing and authority at the provincial level has been raised. Therefore, this study aims to determine cost-effectiveness of the NHS program implementation, in case of eight provinces of China, in order to support evidence-based national policy making in China.

\section{Methods \\ Cost-effectiveness model}

In the present study, we modeled the cost-effectiveness of two screening programs: universal screening which covers all live births, and targeted screening which targets those with one or more risk factors (Figure 1). Universal NHS detects infants with the disorder who have no known risk factors associated with PCEHI, which accounts for approximately $50 \%$ of PCEHI cases $[18,19]$. The targeted screening of newborns with risk factors for hearing impairment is one alternative to universal NHS. Although the universal strategy has been widely recommended as it can detect more cases, recently Joint Committee on Infant Hearing (JCIH) suggested that targeted screening might be more appropriate for developing countries because of cost considerations [20].

A natural history model of all infants with and without hearing impairments was developed to characterize the process of screening, diagnosis and interventions through all possible stages. All neonates annually born in eight provinces (Beijing, Shandong, Hebei, Henan, Jiangxi, Guangxi, Guangdong, and Zhejiang) of China from 2007 to 2009 were simulated (Figure 2). In these 8 provinces of China, Beijing, Shandong, Hebei, Guangdong, and Zhejiang are relatively developed provinces, whereas Henan, Jiangxi, and Guangxi are relatively developing provinces. The model determined the proportion of infants with PCEHI in the simulated cohort who would potentially benefited from the NHS program, where detection by a process of screening and diagnosis occurs before 6 months and intervention before 12 months.

\section{Probability parameters}

Depending on the program coverage and screening strategies, neonates could either receive or not receive screening. Neonates screened consisted of false-positive and false-negative cases, and those with a positive result are referred to the diagnosis center. With the probability of drop-out from the diagnosis center and an inaccessibility of interventions, referred neonates might not be either diagnosed or receive interventions. In the final instance, infants with the disorder would have treated or untreated health outcomes, depending on whether they received screening, diagnosis and interventions.

In this model, probability parameters potentially affecting cost-effectiveness are the proportion of infants with one or more high risks, the prevalence of PCEHI in the general population and high-risk population, the sensitivity, specificity, and coverage of the screening program which shows neonates screened among those 

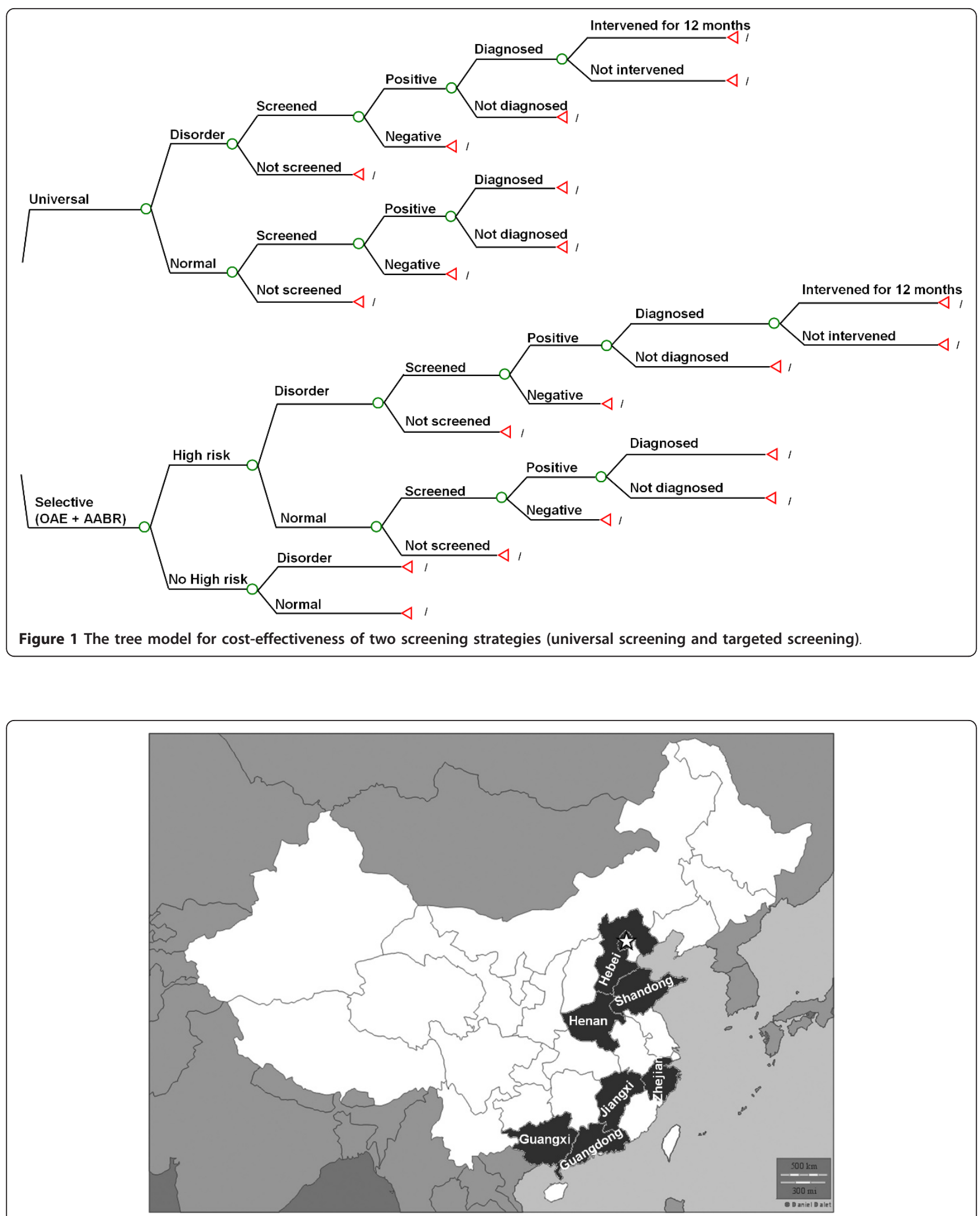

Figure 2 The map of study sites including Beijing (ఓ), Shandong, Hebei, Henan, Jiangxi, Zhejiang, Guangxi and Guangdong 
Table 1 Parameter values and plausible ranges for probability variables used in the baseline and sensitivity analysis

\begin{tabular}{|c|c|c|c|}
\hline Items & Baseline & Range for sensitivity analysis & References \\
\hline High-risk infants & $7 \%$ & $6-8 \%$ & [21] \\
\hline Prevalence in all live-born & $0.30 \%$ & $0.2-0.4 \%$ & $\begin{array}{l}{[22]} \\
{[23]} \\
{[24]} \\
{[25]} \\
{[26]}\end{array}$ \\
\hline Prevalence in high risk infants & $3.00 \%$ & $1.15-3.59 \%$ & $\begin{array}{l}{[27]} \\
{[28]} \\
{[29]} \\
{[30]} \\
{[31]} \\
{[32]}\end{array}$ \\
\hline Sensitivity & $95 \%$ & $90-100 \%$ & $\begin{array}{l}{[17]} \\
{[32]} \\
{[33]}\end{array}$ \\
\hline Specificity & $95 \%$ & $90-100 \%$ & $\begin{array}{l}{[18]} \\
{[34]} \\
{[35]}\end{array}$ \\
\hline Coverage & $60 \%$ & $15-99 \%$ & $\begin{array}{c}{[36]} \\
\text { (Primary data) } \\
\end{array}$ \\
\hline Diagnosis rate & $50 \%$ & $20-95 \%$ & $\begin{array}{c}{[36]} \\
\text { (Primary data) }\end{array}$ \\
\hline Intervention rate & $50 \%$ & $10-95 \%$ & $\begin{array}{c}{[36]} \\
\text { (Primary data) }\end{array}$ \\
\hline
\end{tabular}

targeted by the screening program (general population or high-risk population), diagnosis rate which shows those diagnosed before 6 months among those referred after the screening, and intervention rate which shows infants fitted with hearing aids or cochlear implants and that have started the rehabilitation course before 12 months of age among those with the disorder as detected by the diagnosis process (Table 1). The coverage, diagnosis rate and intervention rate were calculated based on data in the newly established database in the study sites, while others were acquired from literature review.

\section{Costs for the program implementation}

We followed the guideline developed by the World Health Organization (WHO) [37] to estimate costs for the program implementation. These included capital costs (e.g. office buildings, furniture and equipment), recurrent costs such as the salaries of the personnel, materials and supplies, utilities, equipment maintenance, database management, training and transport, and patient-level costs which were composed of the registration fee, screening tests, diagnosis tests, drugs, treatment with a hearing aid, treatment with a cochlear implant, rehabilitation courses, and transportation charges for diagnostic procedures and treatments. The capital investments of office buildings, furniture and equipment were annualized by depreciation, for which the life spans were standardized by Ministry of Finance of the People's
Republic of China and Ministry of Health of the People's Republic of China [38] Table 2 summarized cost estimates for cost-effectiveness analysis. Data for the cost estimates came from the annual financial report of screening facilities, diagnosis centers and rehabilitation facilities in the surveyed provinces, with the cooperation of experts in hospital accounting. Costs were first calculated in RMB, the Chinese currency, with the costs across different years being adjusted in accordance with the price level in 2009 based on the GDP deflator. They were then converted into international dollars (Int\$), by dividing Purchasing Power Parities [39].

Apart from the costs of program implementation for estimates of cost-effectiveness, it is reasonable to assume (and thus estimate) that money would be saved if early detection and intervention was given. Early detection and intervention may bring expenditure on special education and rehabilitation reduction, social and medical services support decrease and incomes increase. However, there was no report on the long-term costs of the disorder from the published literature in China. In our model, we preliminarily attempted to estimate the potential long-term costs saving from the use of the NHS program, including medical services, special education and rehabilitation. It was assumed that improved language outcomes would result in a $10 \%$ decrease in special education costs and a $75 \%$ decrease in vocational rehabilitation costs $[40,41]$. It was estimated based on data from hospitals, disabled people's federations [42] 
Table 2 Parameter values and plausible ranges for cost estimates per case used in the baseline and sensitivity analysis (Int \$)

\begin{tabular}{|c|c|c|c|c|}
\hline \multirow[t]{2}{*}{ Items } & \multirow[t]{2}{*}{ Hearing screening method } & \multirow[t]{2}{*}{ Baseline } & \multicolumn{2}{|c|}{ Ranges for sensitivity analysis } \\
\hline & & & Minimum & Maximum \\
\hline \multicolumn{5}{|l|}{ Screening } \\
\hline \multicolumn{5}{|l|}{ Program costs } \\
\hline \multirow[t]{2}{*}{ Capital costs } & OAE & $240,813,700$ & $170,712,610$ & $307,291,540$ \\
\hline & $\mathrm{OAE}+\mathrm{AABR}$ & $429,951,870$ & $322,027,570$ & $559,461,040$ \\
\hline \multirow[t]{2}{*}{ Recurrent costs } & OAE & 150 & 100 & 200 \\
\hline & $\mathrm{OAE}+\mathrm{AABR}$ & 230 & 130 & 360 \\
\hline Patient costs & & 30 & 10 & 50 \\
\hline \multicolumn{5}{|l|}{ Diagnosis } \\
\hline \multicolumn{5}{|l|}{ Program costs } \\
\hline Capital costs & & $15,950,600$ & $11,014,773$ & $21,467,600$ \\
\hline Recurrent costs & & 240 & 130 & 360 \\
\hline Patient costs & & 170 & 90 & 310 \\
\hline \multicolumn{5}{|l|}{ Intervention } \\
\hline \multicolumn{5}{|l|}{ Program costs } \\
\hline Capital costs & & $13,829,240$ & $12,430,260$ & $15,554,540$ \\
\hline Recurrent costs & & 290 & 200 & 440 \\
\hline Patient costs & & 22,690 & 18,860 & 29,140 \\
\hline
\end{tabular}

Abbreviation: Otoacoustic emission (OAE); Automated auditory brainstem response (AABR)

the provincial health agency and the provincial education agency. Table 3 presented a summary of the longterm costs saving.

\section{Data collection}

Data collection in the field included two components: costs related to the screening program which were acquired from general hospitals and maternal and child health hospitals providing screening and diagnosis services, and rehabilitation facilities, and transition probability parameters including the coverage of screening program, the diagnosis rate and intervention rate which were calculated based on data from the database established at the provincial level. A multiple of three parameters shows the proportion of infants with PCEHI potentially benefiting from the screening program among the targeted population (all or high-risk infants), in this study, calculated as the proportion of the benefit population [43].

After permission to use the database by the district health agencies, the data of the province were acquired. For the costs estimate, all facilities providing screening, diagnosis, and rehabilitation services were visited in selected districts and the annual financial report was analyzed by an expert in hospital accounting.

Table 3 Summary of estimates for long-term costs saving

\begin{tabular}{lll}
\hline \multirow{2}{*}{ Items } & long-term costs saving (Int \$) & \\
\cline { 2 - 3 } & Untreated children with PCEHI & Treated Children with PCEHI \\
\hline Medical services & & \\
\hline \multicolumn{1}{c}{ For cases to fit hearing aid } & 1,960 & 1,960 \\
& $(1,740-2,180)$ & $(1,740-2,180)$ \\
\hline \multicolumn{1}{c}{ For cases to fit cochlear implant } & 40,000 & 40,000 \\
& $(38,000-42,500)$ & $(38,000-42,500)$ \\
\hline Special education & 42,300 & 38,070 \\
(9 years compulsory education) & $(40,500-45,900)$ & $(36,450-41,310)$ \\
\hline Rehabilitation & 82,400 & 20,600 \\
(Up to 15 years) & $(75,200-88,400)$ & $(18,800-22,100)$ \\
\hline Total & 166,660 & 100,630 \\
& $(155,440-178,980)$ & $(60,790-108,090)$ \\
\hline
\end{tabular}




\section{Estimates of health effects}

In this study, population health is expressed as the number of Disability-Adjusted Life Years (DALYs) averted as a result of the screening program. DALYs lost due to PCEHI were calculated as the sum of Years Lost due to Disability (YLDs), as it is a non-fatal disorder, and the time period is life-long. Disability weights for adultonset hearing impairment were adopted in the estimation, 0.216 for untreated disorders and 0.168 for treated disorders, respectively [44]. This was done because there was no evaluation for infants and children, and lifetime coverage rather than childhood coverage was thought to be able to minimize the discrepancy in the long term.

\section{Cost-effectiveness analysis}

The cost-effectiveness of a given intervention is typically expressed as costs per unit of effectiveness, with costs measured in monetary terms and effectiveness measured in health metrics terms. In this study, the average costeffectiveness ratio (ACER) is calculated for each screening strategy by determining the cost for the program's implementation (except long-term costs saving) and total health effects in terms of DALYs averted. Incremental cost-effectiveness ratio (ICER) shows the absolute value of resources necessary to move to the next option. We calculated ICER for different screening strategies by dividing the incremental costs by the incremental health effects, in order to determine the priority of purchasing these services at different budgetary levels.

A multivariate sensitivity analysis was performed to determine uncertainty in health effect estimates and cost-effectiveness ratios, using a probabilistic modeling technique, known as Monte Carlo simulation. The simulation associating the estimates of costs and health effects as described above with each of the transition probability parameters was performed on one parameter at a time allowing for the input of extreme values while keeping the other parameters fixed at the their baseline level. The model was evaluated on 1,000 trials. It showed that any variation in the input parameter might result in a change of preference of strategies compared to the baseline result.

\section{Results}

\section{Benefit population of the current neonatal hearing} screening program

Demographic and socioeconomic information and the indicators of the program implementation including coverage rate, diagnosis rate and intervention rate in the six provinces were presented in Table 4 . The three variables (coverage rate, diagnosis rate and intervention rate) determined the total number of deaf infants finally receiving early interventions and benefiting from the screening program. The benefit population referred to the proportion of infants with the disorder who finally received beneficial early hearing detection and intervention. There was a huge disparity in this figure between different provinces. In general, these figures in the developed eastern provinces were much higher.

\section{Cost-effectiveness of different strategies in eight provinces}

Table 5 shows implementation costs, DALYs averted, and cost-effectiveness of different NHS strategies in eight provinces. Based on GDP per capita in each province and baseline of transition probability parameters, universal strategy shows cost-effectiveness in Guangdong, Shandong, and Beijing, and targeted strategy shows cost-effectiveness in Zhejiang and Hebei, while neither of the screening strategy shows cost-effectiveness in Guangxi, Jiangxi and Henan.

Multivariate sensitivity analyses were performed for transition probability parameters to determine the robustness of the model. The results suggested the variables whose range of uncertainty had a great impact on the cost-effectiveness of the screening strategies were the program coverage, diagnosis rate, and intervention rate. Figure 3 showed that the increasing proportion of the benefit population, which was estimated by multiplying the three variables, reduced ACER of different strategies and gradually helped both reach better costeffectiveness. Targeted strategy trended to be cost-effective in Guangxi, Jiangxi, Henan, Guangdong, Zhejiang, Hebei, Shandong, and Beijing from the level of 9\%, 9\%, $8 \%, 4 \%, 3 \%, 7 \%, 5 \%$, and $2 \%$, respectively; while universal strategy trended to be cost-effective in those provinces from the level of $70 \%, 70 \%, 48 \%, 10 \%, 8 \%, 28 \%, 15 \%$, $4 \%$, respectively.

\section{Economic effects on long-term costs saving}

Costs would be saved if early detection and intervention was given. In our model, universal strategy and targeted strategy led to $214,024,820$ and $104,872,740$ Int $\$$ of long-term costs saving in total which are approximately equivalent to $0.14 \%$ and $0.07 \%$ of the annual health expenditure [36].

At the baseline, both strategies achieve cost savings which were greater than implementation costs. When the proportion of benefit population expanded, the effect of these screening strategies on the long-term costs saving become more and more significant, especially those of universal strategies, exceeding the total costs of the screening program implementation, suggesting a good economic effect in the long term (Figure 4).

\section{Discussion}

WHO has recommended the implementation of NHS program in member states, particularly in developing 
Table 4 Basic information of study sites

\begin{tabular}{|c|c|c|c|c|c|c|c|c|}
\hline Provinces & Beijing & Shandong & Hebei & Zhejiang & Guangdong & Henan & Jiangxi & Guangxi \\
\hline Population $^{a}$ & $16,330,000$ & $93,670,000$ & $69,430,000$ & $50,600,000$ & $94,490,000$ & $93,600,000$ & $4,368,000$ & $47,680,000$ \\
\hline Birth rate (per 1,000$)^{a}$ & 8.32 & 11.11 & 13.33 & 11.26 & 11.96 & 11.26 & 13.86 & 14.19 \\
\hline No. of live births per year ${ }^{a}$ & 135,866 & $1,040,674$ & 925,502 & $1,053,936$ & $1,130,100$ & $1,053,936$ & 605,405 & 676,579 \\
\hline GDP per capita $(\operatorname{Int} \$)^{b}$ & $16,644.25$ & $7,951.80$ & $5,684.11$ & $10,698.20$ & $9,479.99$ & $4,578.86$ & $3,612.58$ & $3,590.28$ \\
\hline Life expectancy ${ }^{a}$ & 76.1 & 73.92 & 72.54 & 74.7 & 73.27 & 71.54 & 68.95 & 71.29 \\
\hline Development status $^{c}$ & Developed & Developed & Developed & Developed & Developed & $\begin{array}{l}\text { Moderately } \\
\text { developed }\end{array}$ & $\begin{array}{l}\text { Moderately } \\
\text { developed }\end{array}$ & $\begin{array}{l}\text { Less } \\
\text { developed }\end{array}$ \\
\hline No. of screening facilities ${ }^{a}$ & 548 & 1,402 & 1,296 & 722 & 1,154 & 1,341 & 602 & 553 \\
\hline No. of diagnosis centers ${ }^{a}$ & 6 & 17 & 11 & 11 & 21 & 17 & 11 & 14 \\
\hline $\begin{array}{l}\text { No. of rehabilitation } \\
\text { facilities }^{\mathrm{a}}\end{array}$ & 12 & 14 & 8 & 8 & 15 & 10 & 6 & 5 \\
\hline Coverage rate $^{d}$ & $97.8 \%$ & $83.3 \%$ & $91.3 \%$ & $83.3 \%$ & $97.0 \%$ & $24.5 \%$ & $30.5 \%$ & $50.2 \%$ \\
\hline Diagnosis rate ${ }^{d}$ & $97.4 \%$ & $68.3 \%$ & $60.0 \%$ & $60.0 \%$ & $75.0 \%$ & $30.2 \%$ & $48.2 \%$ & $21.4 \%$ \\
\hline Intervention rate ${ }^{d}$ & $77.1 \%$ & $72.5 \%$ & $76.1 \%$ & $70.0 \%$ & $75.0 \%$ & $23.8 \%$ & $33.3 \%$ & $23.9 \%$ \\
\hline $\begin{array}{l}\text { Proportion of benefit } \\
\text { population }\end{array}$ & $73.4 \%$ & $41.3 \%$ & $41.7 \%$ & $35.0 \%$ & $54.6 \%$ & $1.8 \%$ & $4.9 \%$ & $2.6 \%$ \\
\hline
\end{tabular}

Data source:

a: Ministry of Health of the People's Republic of China [17].

b: International Monetary Fund [39].

c: Ministry of Health of the People's Republic of China [35].

d: Provincial data

countries, based on the experiences and contributions of leading experts from various world regions and across relevant disciplines [45]. This study found there was a huge disparity in the implementation of the NHS program in the surveyed provinces. In general, those developed provinces had much higher program coverage, diagnosis rates and intervention rates, leading to a larger benefit population and helping the NHS program achieve better cost-effectiveness. In fact, the NHS program had been adopted several years in some developed provinces in China with financial and administrative supports by local health government [46]. Under the decentralization of health financing, the developed provinces have a stronger financial capacity to invest in health programs [47]. This difference in implementation and in underlying financial factors has also been reflected in the national plan. Regarding the accessibility of the screening, diagnosis and intervention services, the short-term goal is to achieve a coverage rate of $80 \%$ in the eastern provinces (the most developed region of China), $40 \%$ in the moderate provinces, and 30\% in the western provinces (the least developed region of China) by 2012 , and to increase these figures to $90 \%, 60 \%$ and $50 \%$, respectively, by 2015 [17].

Can the national plan help the NHS program achieve its goal with good cost-effectiveness, health and longterm economic effects, at both the national and the regional level? The goal of the NHS program in China

Table 5 Implementation costs, health effects and cost-effectiveness of different NHS strategies in eight provinces

\begin{tabular}{|c|c|c|c|c|c|c|c|c|}
\hline Items & Guangxi & Jiangxi & Henan & Guangdong & Zhejiang & Hebei & Shandong & Beijing \\
\hline \multicolumn{9}{|l|}{ Total costs (Int \$) } \\
\hline Universal strategy & $10,498,335$ & $23,063,105$ & $9,121,907$ & $39,077,961$ & $17,144,588$ & $33,472,076$ & $32,326,020$ & $4,014,771$ \\
\hline Targeted strategy & $1,416,185$ & $2,272,838$ & $2,403,868$ & $6,774,350$ & $2,022,018$ & $4,554,258$ & $4,880,764$ & $1,094,184$ \\
\hline \multicolumn{9}{|l|}{ DALY averted } \\
\hline Universal strategy & 35 & 206 & 78 & 3,508 & 278 & 1,499 & 1,533 & 292 \\
\hline Targeted strategy & 17 & 101 & 38 & 1,719 & 136 & 735 & 751 & 143 \\
\hline \multicolumn{9}{|l|}{ ACER } \\
\hline Universal strategy & 299,952 & 111,957 & 116,948 & 11,140 & 61,671 & 22,330 & 21,087 & 13,749 \\
\hline Targeted strategy & 83,305 & 22,503 & 63,260 & 3,941 & 14,868 & 6,196 & 6,499 & 7,652 \\
\hline Reference (3 times GDP per capita) & 10,771 & 10,838 & 13,737 & 28,440 & 32,095 & 17,052 & 23,855 & 49,933 \\
\hline \multicolumn{9}{|l|}{ ICER } \\
\hline Universal strategy & 504,564 & 198,003 & 167,951 & 18,057 & 106,497 & 37,851 & 35,096 & 19,601 \\
\hline Targeted strategy & 83,305 & 22,503 & 63,260 & 3,941 & 14,868 & 6,196 & 6,499 & 7,652 \\
\hline
\end{tabular}




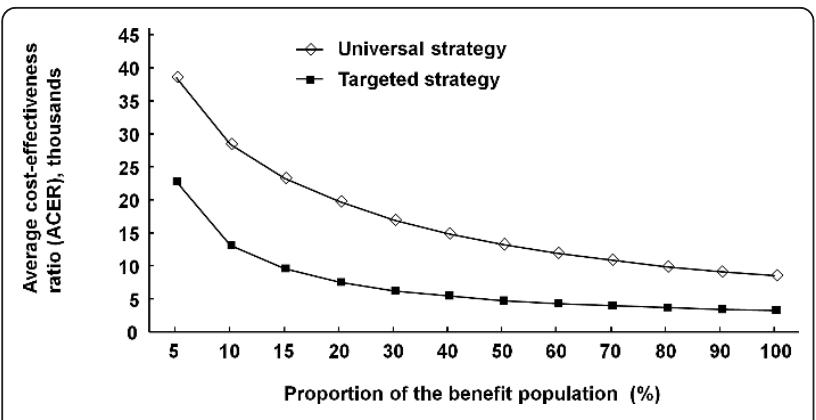

Figure 3 The relationship of the average cost-effectiveness ratio (ACER) and the proportion of benefit population for two screening strategies (universal screening and targeted screening).

is to establish a nationwide hospital-based universal program and to continuously expand diagnosis and intervention services [17]. The rationale for implementing a universal strategy is that it can detect more deaf infants, providing a greater opportunity for them to experience normal language development, while also providing overall benefits in terms of the reduction in disability and the improvement in health and well-being of the Chinese population. As the program's implementation varies by different socioeconomic development status, a sufficiently high coverage rate, diagnosis rate and intervention rate ensure that the universal strategy achieves good cost-effectiveness and the relevant health and economic effects in Beijing, Shandong and Hebei; but in the other three provinces Henan, Jiangxi and Guangxi, where these three indicators were low, targeted strategies tend to be more feasible, similar to previous policy suggestions that have been advanced in relation to developing countries [20,48]. Meanwhile, a pilot survey on context-specific risk factors for PCEHI in diverse settings should be implemented to facilitate the targeted strategy.

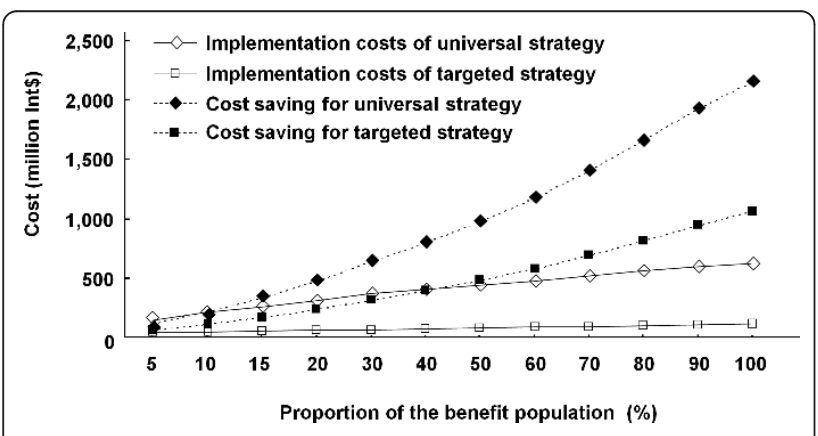

Figure 4 The relationship of the long-term costs saving or implementation costs of two screening strategies (universal screening and targeted screening) and the proportion of benefit population
The study also attempted to estimate the long-term economic effect of the NHS program in China. As the available data and evidence is limited and this is a very preliminary approach, only costs saving in rehabilitation and special education up to 15 years of age (at which children finish their compulsory education) were counted, potentially leading to an underestimate of the economic effect. Even so, the results showed that at the baseline, the costs saved already exceeded the implementation costs in the targeted strategies; as the proportion of the benefit population expends, the economic effect would be more and more significant, especially in relation to universal strategies. Such results strongly support the implementation of the NHS program and suggest potentially greater benefits of adopting universal strategies in China.

Our study was restricted by the limited availability of data and evidence. First, globally, there was no strong evidence based on randomized controlled trials for the effectiveness of NHS on deaf infants' language development, and consequently, no evidence as regards the evaluation of their psychological and educational-related outcomes. The impact of early intervention on longterm cost saving remains unknown. Moreover, in China, there has been no previous nationwide population-based study to survey the epidemiological status of PCEHI. Data on the prevalence used in this study were therefore derived from a crude estimation based on the number of the hearing disabled population and a few regional surveys. All that needs to be researched in future. Last, due to the unavailability of child-onset disability weights for hearing loss, we attempted to use adult-onset disability weights instead into the economic evaluation. It may underestimate the health effects of NHS as early detection and intervention leads to much more benefits on children's language development.

\section{Conclusions}

In conclusion, universal strategy can be considered as the ultimate implementation goal as it provides the best health and economic effects. A universal strategy is feasible in provinces where screening, diagnosis and intervention services are good enough to benefit sufficient proportion of the deaf children. In the other regions, a targeted strategy is temporarily more realistic than a universal strategy; however, related services still need to be scaled up to cover the targeted population as much as possible. The reference data from this study thus are expected to be of particular benefit in terms of the 'rolling out' of the national plan.

\section{Abbreviations}

PCEHI: Permanent congenital and early-onset hearing impairment; NHS: Neonatal hearing screening; CEA: Cost-effectiveness analysis; DALYs: 
Disability-Adjusted Life Years; YLDs: Years Lost due to Disability; ACER: Average cost-effectiveness ratio; ICER: Incremental cost-effectiveness ratio.

\section{Acknowledgements}

We sincerely thank Guangdong Province Maternal and Child Health Hospital, Jiangxi Province Jiujiang City Maternal and Child Health Hospital, Hebei Province Langfang City Maternal and Child Health Hospital, Beijing HaiDian District Maternal and Child Heath Hospital, The Third People's Hospital of Wenzhou City (Zhejiang Province), Henan Province Anyang City Maternal and Child Heath Hospital, Guangxi Province Liuzhou City Maternal and Child Heath Hospital, Beijing Shangdi Hospital, Hebei Province Chengde City Maternal and Child Health Hospital, and all experts from local health agencies and related health and rehabilitation facilities for their cooperation and support.

\section{Author details}

${ }^{1}$ Beijing Tongren Hospital, Capital Medical University, Beijing, China. ${ }^{2}$ Beijing Institute of Otolaryngology, Key Laboratory of Otolaryngology Head and Neck Surgery (Capital Medical University), Ministry of Education, China, 17 Hou-gou Lane, Chong-nei Street, Beijing 100005, China. ${ }^{3}$ Graduate School of Medicine, The University of Tokyo, Tokyo, Japan. "Tokyo University Hospital, Tokyo, Japan. ${ }^{5}$ Institute of Social Medicine and Health Services Management, School of Public Health, Shandong University, Wen-hua-xi Road No.44, Jinan City, Shandong Province 250012, China. ${ }^{6}$ Guangdong Province Maternal and Child Health Hospital, Guangzhou, Guangdong, China. ${ }^{7}$ Beijing Haidian District Maternal and Child Heath Hospital, Beijing, China. ${ }^{8}$ Hebei Province Langfang City Maternal and Child Health Hospital, Langfang, Hebei, China. ${ }^{9}$ Henan Province Anyang City Maternal and Child Heath Hospital, Anyang, Henan, China. ${ }^{10}$ Jiangxi Province Jiujiang City Maternal and Child Health Hospital, Jiujiang, Jiangxi, China. ${ }^{11}$ Guangxi Province Liuzhou City Maternal and Child Heath Hospital, Liuzhou, Guangxi, China. ${ }^{12}$ Beijing Shangdi Hospital, Beijing, China. ${ }^{13}$ The Third People's Hospital of Wenzhou City, Wenzhou, Zhejiang, China. ${ }^{14}$ Hebei Province Chengde City Maternal and Child Health Hospital, Chengde, Hebei, China. ${ }^{15}$ Hebei Province Tangshan City Maternal and Child Health Hospital, Tangshan, Hebei, China.

\section{Authors' contributions}

WT, LZX and DMH designed the study. LHH, LZ, RYGT, FHQ, LS, YT, QLK, FM, XFZ, MZ, RLY, LT, HHL, YQG, SNX, XYY, XDL, BEQ and XHC collected data for the study. LHH, LZ, RYGT and FHQ analyzed the data and contributed to the writing of the paper.

\section{Competing interests}

The authors declare that they have no competing interests.

Received: 8 June 2011 Accepted: 17 April 2012 Published: 17 April 2012

\section{References}

1. Sininger YS, Doyle KJ, Moore JK: The case for early identification of hearing loss in children. Auditory system development, experimental auditory deprivation, and development of speech perception and hearing. Pediatr Clin North Am 1999, 46:1-14.

2. Huang L, Han D, Guo Y, Cui XY, Mo LY, Qi BE, Cai ZH, Liu H, En H, Guo LS: Audiological characteristics of infants with abnormal transient evoked otoacoustic emission and normal auditory brainstem response. Biosci Trends 2008, 2:211-215.

3. Moeller MP: Early intervention and language development in children who are deaf and hard of hearing. Pediatrics 2000, 106:E43.

4. Kennedy CR, McCann DC, Campbell MJ, Law CM, Mullee M, Petrou S, Watkin P, Worsfold S, Yuen HM, Stevenson J: Language ability after early detection of permanent childhood hearing impairment. $N$ Engl J Med 2006, 354:2131-2141.

5. Yoshinaga-Itano C, Sedey AL, Coulter DK, Mehl AL: Language of early and later-identified children with hearing loss. Pediatrics 1998, 102:1161-1171.

6. Yoshinaga-Itano C, Coulter D, Thomson V: The Colorado Newborn Hearing Screening Project: Effects on speech and language development for children with hearing loss. J Perinatol 2000, 20:S132-S137.

7. Yoshinaga-Itano C: Universal newborn hearing screening program and developmental outcomes. Audiol Med 2003, 1:199-206.
8. Olusanya $\mathrm{BO}$, Ruben RJ, Parving A: Reduction the burden of communication disorders in the developing world: An opportunity for the millennium development project. JAMA 2006, 296:441-444.

9. Olusanya BO, Newton VE: Global burden of childhood hearing impairment and disease control priorities for developing countries. Lancet 2007, 369:1314-1317.

10. Olusanya BO: Addressing the global neglect of childhood hearing impairment in developing countries. PLoS Med 2007, 4:e74.

11. Huang L, Gai R: 2008 Beijing Symposium on a Hearing Screening Program for Neonates and Children: Perspectives on interdisciplinary and international collaboration. Biosci Trends 2008, 2:216-217.

12. Puig Reixach MT, Municio A, Medà MC: WITHDRAWN. Universal neonatal hearing screening versus selective screening as part of the management of childhood deafness. Cochrane Database Syst Rev 2010, 1:CD003731.

13. Lopez AD, Mathers CD, Ezzati M, Jamison DT, Murray CJ: Global and regional burden of disease and risk factors, 2001: systematic analysis of population health data. Lancet 2006, 367:1747-1757.

14. Jamison DT, Mosley WH: Disease control priorities in developing countries: health policy responses to epidemiological change. Am J Public Health 1991, 81:15-22.

15. Uus K, Bamford J, Taylor R: An analysis of the costs of implementing the National Newborn Hearing Screening Programme in England. J Med Screen 2006, 13:14-19.

16. Baltussen $R$, Smith $A$ : Cost-effectiveness of selected interventions for hearing impairment in Africa and Asia: A mathematical modeling approach. Int J Audiol 2009, 48:144-158.

17. Ministry of Health of the People's Republic of China: The National Neonatal Congenital Disease Screening Plan.[http://www.moh.gov.cn/ publicfiles/business/htmlfiles/mohbgt/s10695/200911/44716.htm].

18. Davis A, Bamford J, Wilson I, Ramkalawan T, Forshaw M, Wright S: A critical review of the role of neonatal hearing screening in the detection of congenital hearing impairment. Health Technol Assess 1997, 1(i-iv):1-176.

19. Early identification of hearing impairment in infants and young children: NIH Consensus Development Conference. Int I Pediatr Otorhinolaryngol 1993, 27:201-202.

20. American Academy of Pediatrics: Joint Committee on Infant Hearing: Year 2007 position statement: Principles and guidelines for early hearing detection and intervention programs. Pediatrics 2007, 120:898-921.

21. Puig T, Municio A, Medà C: Universal neonatal hearing screening versus selective screening as part of the management of childhood deafness. Cochrane Database Syst Rev 2005, , 2: CD003731, DOl: 10.1002/14651858. CD003731.pub3.

22. Hou Z, Wu H, Tao Z, Li Y: Clinical analysis of the 2005 UNHS results obtained in Shanghai. J Audiol Speech Pathol 2008, 16:206-209.

23. Sun Z, Li J, Sun C: Study of hearing screening for newborns in Heze area. Chinese J Birth Health Hered 2007, 15:82-84.

24. Pan J: Analysis of risk factors and intervention on 16,567 cases of newborn hearing screening. Chinese J Perinat Med 2006, 9:275-276.

25. Xu Z, Shen X, Sun X: Review and perspective of implementation of neonatal hearing screening program in Shanghai. J Audiol Speech Pathol 2007, 15:277-278.

26. Wen X, Wei M: Analysis of 33,719 cases of newborn hearing screening. Maternal Child Health Care China 2008, 23:2825-2826.

27. Zhao P, Xu Z, Wu S: Hearing screening for high-risk newborns. Nat Med J China 2003, 83:285-288.

28. Chen Y, Zhang Y, Guo Q, Ye C, Peng S: Hearing screening in high risk newborns and research of high risk factors of hearing loss in newborns. J Clin Otorhinolaryngol Head Neck Surg 2008, 22:737-739.

29. Huang L, Huang W, Liu Y, Luo J: Study on screening for newborn hearing high risk neonates. Mod Prev Med 2009, 36:1844-1846.

30. Mai $F$, Lai $Q, W u$ Y, Chen Y: Analysis of hearing loss among high-risk infants. Matern Child Health Care China 2008, 20:2831-2832.

31. Hu J, Xie Z, Chen P: Hearing screening and risk factors in high-risk infants. Nat Med J China 2006, 86:2567-2568.

32. Chen L: Analysis of hearing screening results among 1993 high-risk infants. Chin J Child Health Care 2009, 17:103-104.

33. Agence Nationale d' Accréditation et d' Evvaluation en Santé (ANAES): Evaluation Clinique et économique du dépistage neonatal de la surdité permanente par les otoémissions acoustiques.[http://www.has-sante.fr/ 
portail/jcms/c_464137/evaluation-clinique-et-economique-du-depistageneonatal-de-la-surdite-permanente-par-les-otoemissions-acoustiques].

34. Kennedy C, McCann DC, Campbell MJ, Kimm L, Thornton R: Universal newborn screening for permanent childhood hearing impairment: an 8year follw-up of a controlled trial. Lancet 2005, 366:660-662.

35. Ministry of Health, China: An Analysis Report of National Health Services Survey in China, 2008.[http://www.moh.gov.cn/publicfiles/business/ htmlfiles/mohwsbwstjxxzx/s8211/201009/49165.htm].

36. Ministry of Health of the People's Republic of China: China Health Statistics Year book 2010.[http://www.moh.gov.cn/publicfiles/business/ htmlfiles/zwgkzt/ptjnj/year2010/index2010.html].

37. Tan-Torres Edejer T, Baltussen RM, Asdam T, Hutubessy RC, Acharya A, Evans DB, Murray CJ: Making choices in health: WHO guide to costeffectiveness analysis Geneva: WHO; 2003.

38. Ministry of Finance of the People's Republic of China and Ministry of Health of the People's Republic of China Hospital accounting system. [http://hk.lexiscn.com/law/law-chinese-1-4134.html].

39. Silver M: International Monetary Fund applications of purchasing power parity estimates.[http://www.imf.org/external/pubs/ft/wp/2010/wp10253. pdf].

40. Keren R, Helfand M, Homer C, McPhillips H, Lieu TA: Projected costeffectiveness of statewide universal newborn hearing screening. Pediatrics 2002, 110:855-864.

41. Cheng AK, Rubin HR, Powe NR, Mellon NK, Francis HW, Niparko JK: Costutility analysis of the cochlear implant in children. JAMA 2000, 284:850-856

42. China Disabled Persons' Federation: The second national sample survey on disability in 2006.[http://www.cdpf.org.cn/sjcx/node_50872.htm].

43. Han DM: Universal Newborn Hearing Screening Beijing: People's Medical Publishing House; 2003.

44. Mathers C, Smith A, Concha M: Global burden of hearing loss in the year 2000.[http://www.who.int/healthinfo/statistics/bod_hearingloss.pdf].

45. Olusanya BO: Highlights of the new WHO Reports on Newborn and Infant Hearing Screening and implications for developing countries. Int J Pediatr Otorhinolaryngol 2011, 75:745-748.

46. Shen $\mathrm{X}$ : The current status of the neonatal hearing screening program in China. Nat Med J China 2003, 83:266-267.

47. Meng Q, Li R, Cheng G, Blas E: Provision and financial burden of TB services in a financially decentralized system: a case study from Shandong, China. Int J Health Plann Manage 2004, 19:S45-S62.

48. Sivalal S: Health technology assessment in the Asia Pacific region. Int $\mathrm{J}$ Technol Assess Health Care 2009, 25(Suppl 1):196-201.

\section{Pre-publication history}

The pre-publication history for this paper can be accessed here: http://www.biomedcentral.com/1472-6963/12/97/prepub

doi:10.1186/1472-6963-12-97

Cite this article as: Huang et al:: Cost-effectiveness analysis of neonatal hearing screening program in china: should universal screening be prioritized? BMC Health Services Research 2012 12:97.

\section{Submit your next manuscript to BioMed Central and take full advantage of:}

- Convenient online submission

- Thorough peer review

- No space constraints or color figure charges

- Immediate publication on acceptance

- Inclusion in PubMed, CAS, Scopus and Google Scholar

- Research which is freely available for redistribution

Submit your manuscript at www.biomedcentral.com/submit
C Biomed Central 